\title{
Language Sensitive Health Education - Lessons from the Field
}

\author{
Mary Portis \\ California State University, Chico
}

\begin{abstract}
In these times of language diverse communities, it is difficult to present health education programs in the first language of every participant. Use of language-sensitive techniques helps those with limited English to understand the health message and learn health skills. This article describes simple techniques that can be incorporated into any program serving low income, language-diverse populations.

En estos tiempos de comunidades con diversos idiomas, es muy difícil de presentar programas educativos de salud en el primer idioma de cada participante. El uso de técnicas que sean sensitivas a diversos idiomas ayudan a aquellos con Ingles limitado a entender el mensaje de salud, al igual que aprender destrezas de salud. Este artículo describe técnicas simples que pueden ser incorporadas en cualquier programa que provea servicios a poblaciones de bajo ingreso y diversos idiomas.
\end{abstract}

(C) 2003 Californian Journal of Health Promotion. All rights reserved.

Keywords: Language sensitive, health education, California State University, Chico

\section{Introduction}

Our community outreach programs serve a diverse population with over 60 percent speaking a first language other than English. Spanish is the most common first language but rarely is a program attended entirely by Spanish speakers. In order to provide the best service possible we frequently use translators and provide written materials in the represented languages, but we have found that the techniques described in this paper are equally important in getting language diverse individuals to attend our programs.

\section{An Overview of Our Programs}

We have six programs that serve language diverse audiences. These programs are described below.

Health Screening for Preschool Children: A day of free health screening for children under age 6 is scheduled each fall for low income families (see Figure 1). In addition to vision, hearing, height, weight, immunizations, and nutritional status screenings, parents can learn about SIDS, fire safety, healthy snacks, childproofing the home, asthma and allergies. Breakfast is provided.

\section{Hypertension Screening and Education:} Many times per year at various informal sites around our community, we provide free blood pressure screening, individual record keeping cards, and personalized education about the blood pressure reading (see Figure 2).

Diabetes Screening and Education: Twice per year we provide free educational programs on diabetes where participants can test their blood sugar and receive referrals for further medical attention (see Figure 3). 


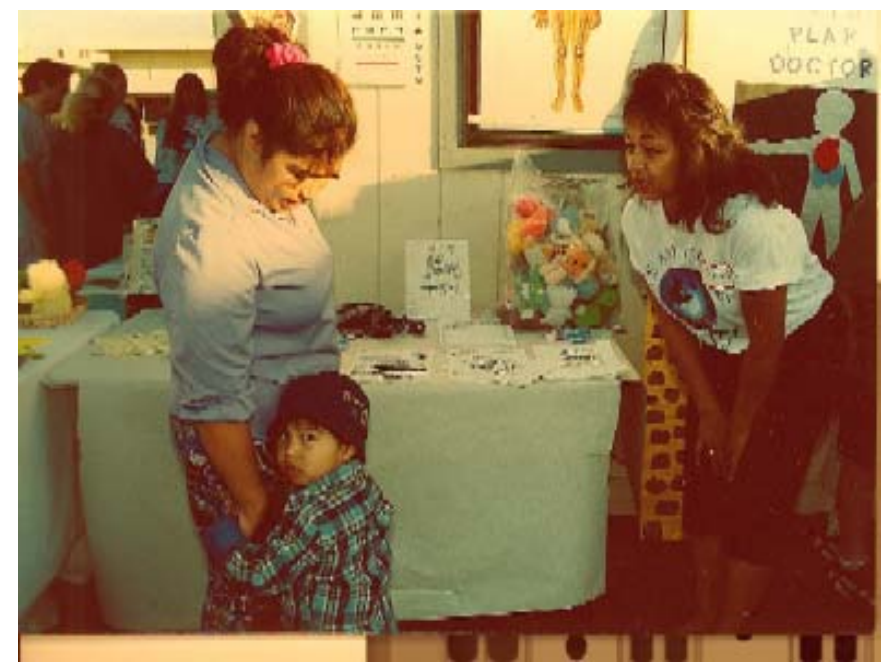

Figure 1

Mother and Child at Health Screening

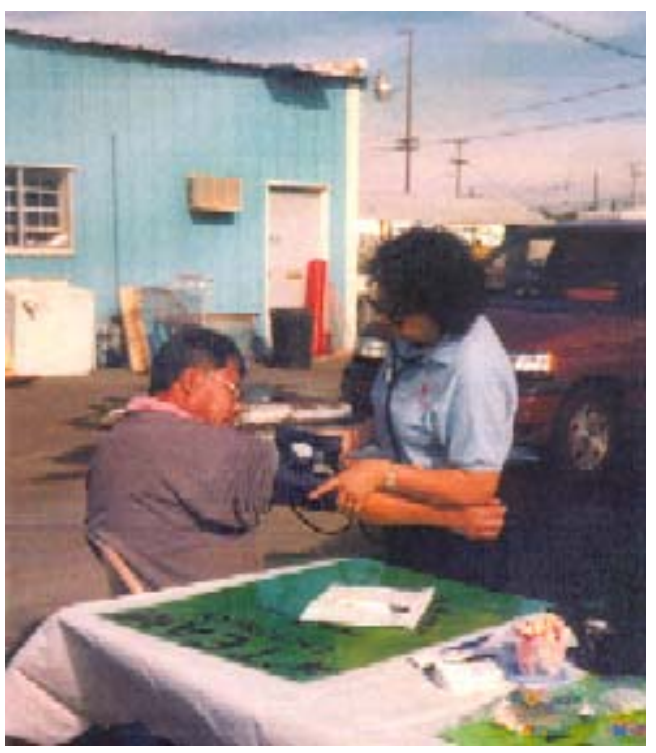

Figure 2

Hypertension Screening in Store Parking Lot

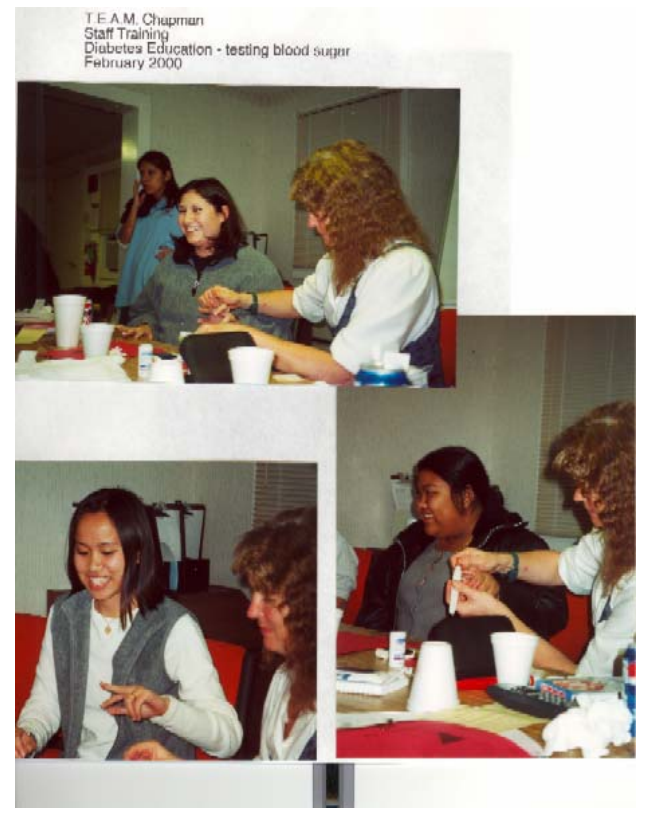

Figure 3

Testing Blood Sugar

Health Academy: At various rural and mountain elementary schools, Health Academy meets for a full school day (see Figure 4). Students in grades kindergarten through sixth grade participate in active, age-appropriate health education lessons. The topics of these lessons include: water safety, fire safety, first aid, nutrition, environmental health, going to the 
doctor, dental health, health careers, physical fitness, stress management and drug and alcohol prevention.

\section{Physical Fitness and Parenting for Spanish}

Speaking Mothers: Twice a week for two

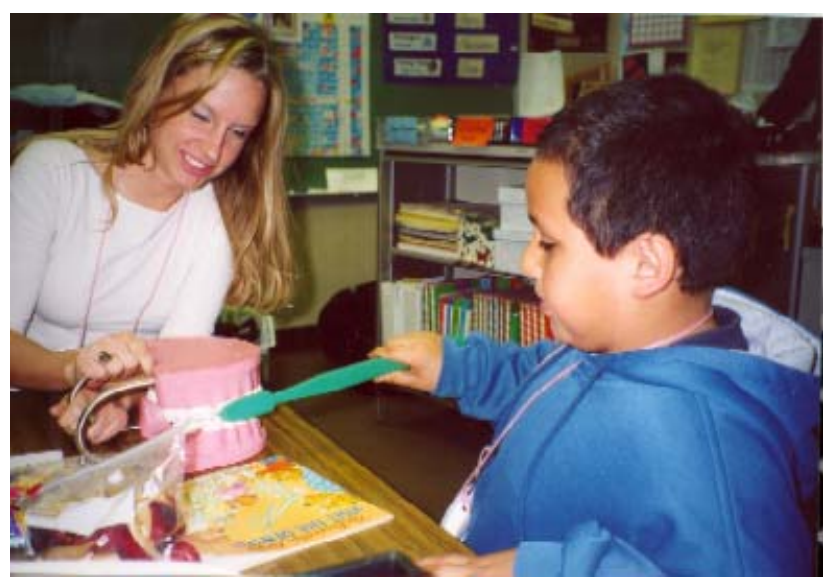

Figure 4

Dental Health at Health Academy hours, Spanish-speaking women with children under school age meet to exercise, learn ageappropriate activities for their children and discuss parenting issues (see Figure 5).

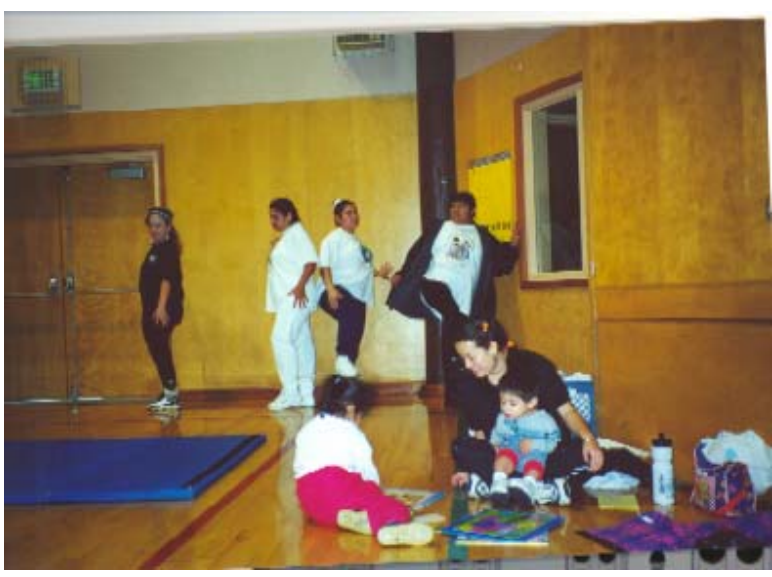

Figure 5

Mothers Warming Up for an Exercise Session

(see Figures 6 \& 7). Separate sessions are scheduled for junior high and high school participants.
Leaders for a Lifetime: Youth ages 12 to 18 meet weekly to enhance their leadership skills through exposure to variety of academic, career, recreational, and community service activities
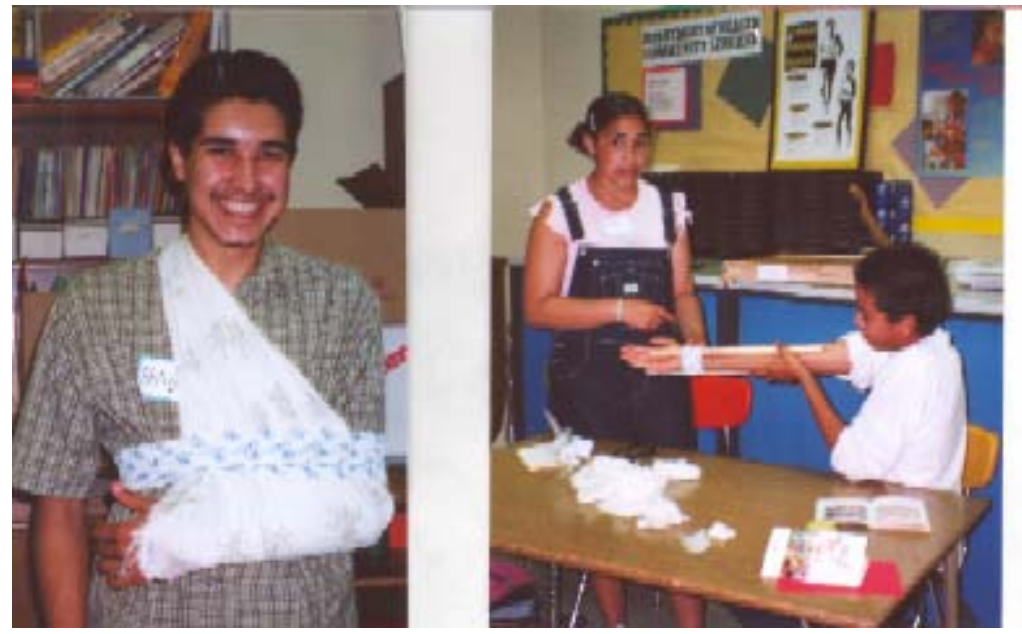

Figure 6

High School Leaders Learn Emergency First Aid Procedures 


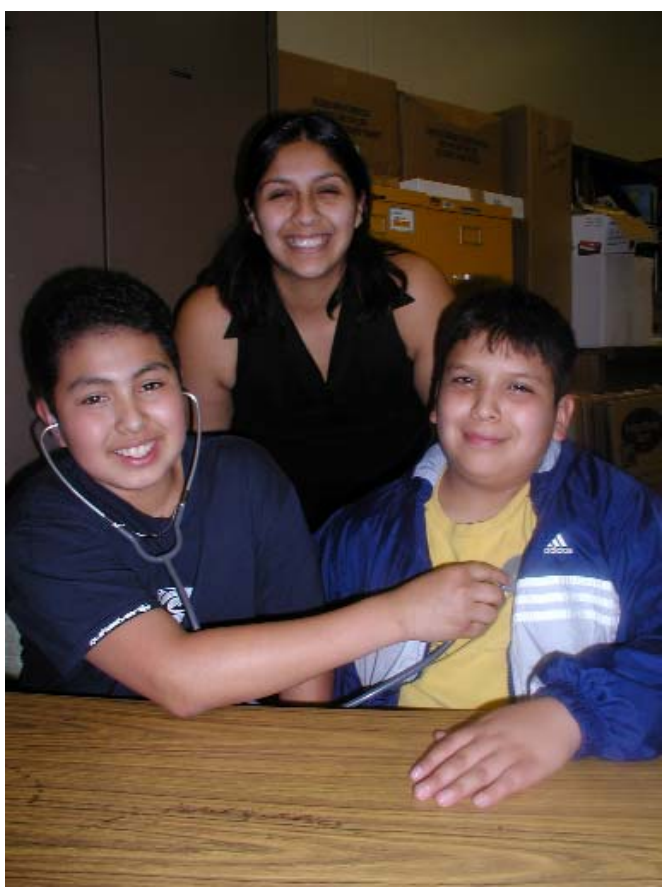

Figure 7

Junior High Leaders Learn About Health Careers

\section{Language Sensitive Techniques}

Over a five year period we have experimented with a variety of formats and approaches when serving our language diverse community. Our experiments continue to indicate that the following features are the keys to success to recruiting, educating and maintaining a connection with our language diverse residents.

\section{Feature 1: Create a Relationship}

Relationship is important to Spanish speaking audiences as well as other language diverse groups. We like to greet our participants with hellos in English and in their first language by a series of greeters that represent each language group. We provide name tags to facilitate conversation. We offer food and drinks, and sometimes a free raffle. Our greeters mingle through the participants and help them find seats (see Figure 8). If we start a program at 7:00 p.m. we know that the first twenty minutes will be an informal gathering with conversations, food and introductions. Everyone will know the people sitting to either side of them when the formal program starts. Those participants whose English is limited can seat themselves next to others who are more proficient.

Health educators from settings such as schools, hospitals, voluntary agencies and health departments have expressed impatience with our starting ritual when they have been invited to participate. They often say things like, "I though you said this was going to start at 7:00 p.m." or "Whose organizing this? These people are just wandering around." They see the minutes spent creating a welcoming environment as a waste of valuable time. Our participants on the other hand enjoy this time because it helps them to feel included and connected. It's fun. It's social. It's a nice place to be. The health education message that is coming is important but it is okay to enjoy oneself in the process of hearing that message, and the message is no more important than developing a support network in one's community. 


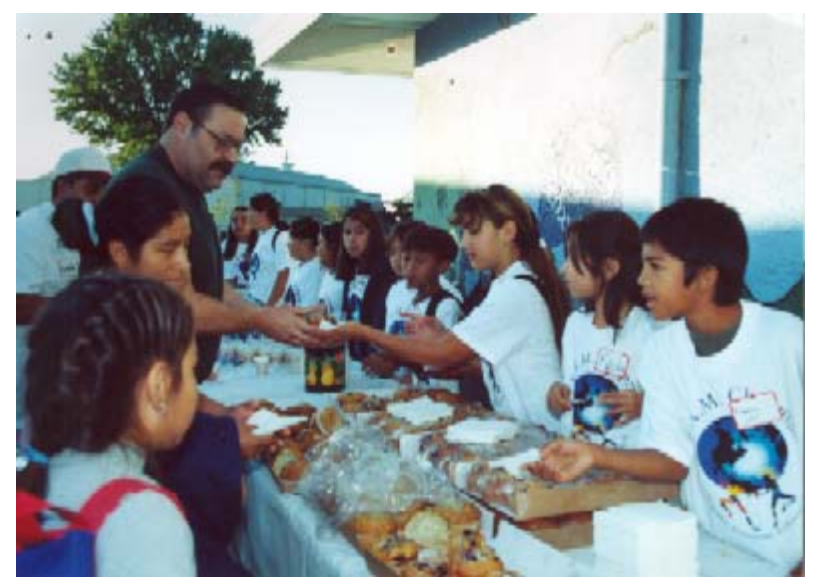

Figure 8

Community Children Acting as Greeters and Food Servers for a Health Education Program

\section{Feature 2: Focus on the People}

Once the formal program starts we use group voting and stand up/sit down games to see what the audience knows about the topic. From there we focus on the information that relates directly to the actions the audience should take or the skills the audience should develop.

\section{Feature 3: Reduce the Words}

It is easy to talk too much and to include too many written words on transparencies and PowerPoint presentations. While it may seem like the lectures and prepared slides demonstrate knowledge and preparation to present the information, these teaching methods are really just a short cut. Real preparation for a limited English-speaking audience means pictures, demonstrations, video clips, role play, and examples of the items being discussed. Think visual (see Figure 9). Think images. Take out the words that are jargon or have too many syllables.

We leave the background information, research study findings, charts, graphs, and statistics at the office. This information may be interesting to a professional audience but it doesn't translate into action or to the vocabulary understood by limited English speakers.

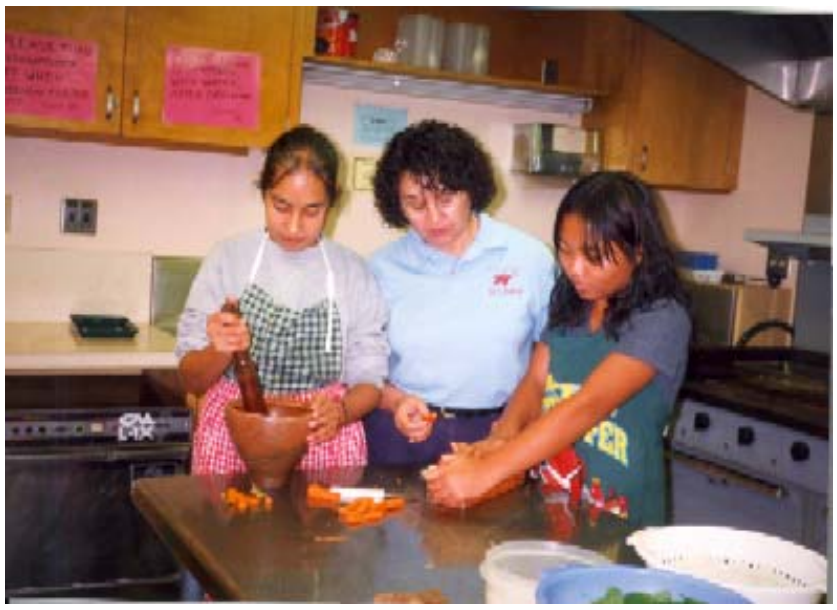

Figure 9

Learning About Heart Healthy Nutrition Through Food Preparation 


\section{Feature 4: Emphasize Action}

Scary facts, warnings and lists of don'ts may cause concern and a desire to find out more, but with our audiences these approaches cause glazed over eyes and a desire to get out of the room. Limited English audiences need action (see Figure 10). Use the technique "I do, we do, you do," when presenting a topic.

"I do" refers to the health educator. In a lung health program, demonstrate to the audience how lung capacity is measured.

"We do" refers to the group as a whole. With the health educator as a guide, take everyone's lung capacity, explaining the steps and scores along the way.

"You do" refers to each individual. Allow everyone to practice taking their own lung capacity.

If a health topic is worth talking about then there is some action that should be taken to prevent it, control it, treat it or live with it. When those actions are the focus of a program the audience goes home with new skills and new personal power in their lives.

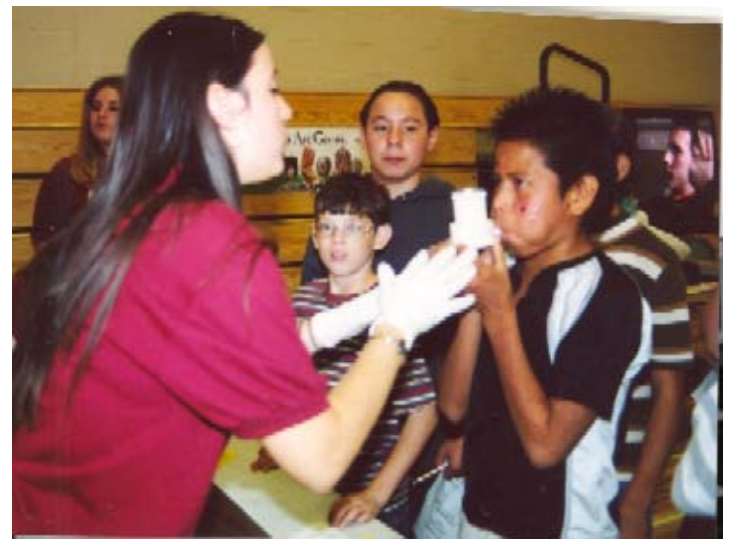

Figure 10

Testing Lung Capacity

Feature 5: Invite the Whole Family

Limited English audiences will attend a health education program more readily if children are welcome. This does not mean having a child drop off area separate from the parents. No one wants to drop off their children with unknown adults especially if those adults speak another language. Instead, expect families to keep their infants and toddlers with them during the program. Pay positive attention to the presence of these small children and realize that there will be some extra noise. Provide a beneficial program for the preschool through school age children that mirrors the information the parents are learning or presents a fun, active, creative set of activities planned for a variety of ages. Keep all the children together. Younger children are more secure when their older siblings are included and older siblings are used to taking care of their brothers and sisters. Activities aimed at the six to nine year old age group can be implemented well with an age range of three to twelve (see Figure 11). The older children help the younger ones and those in the target age range work independently. When the children are happy, included and receiving a program made just for them, the parents are more likely to relax and focus their attention toward the health education program. 


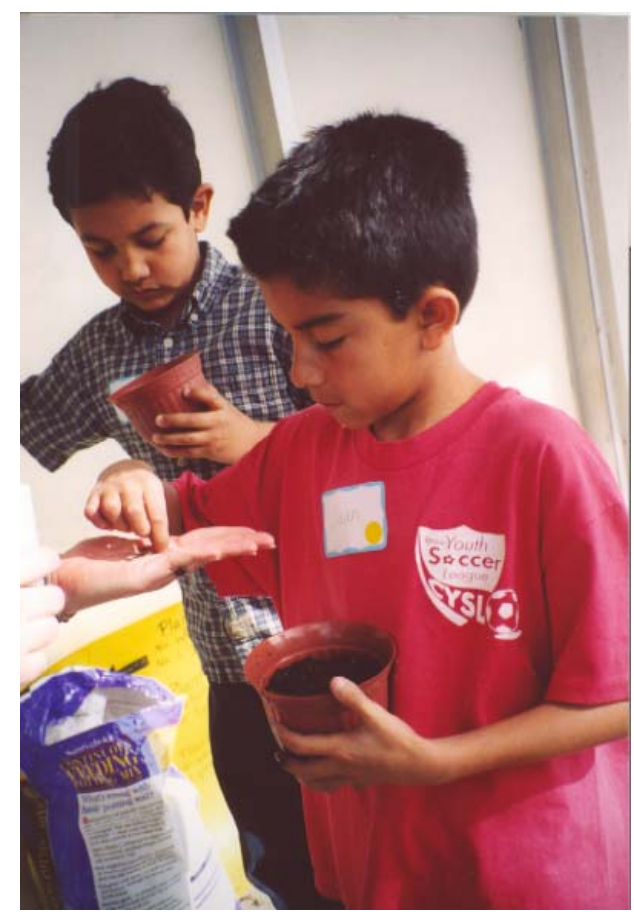

Figure 11

Boys Participating in an Environmental Project While Parents Attend a Health Education Program

\section{Feature 6: Choose Accessible, Comfortable Program Sites \\ When deciding where to hold health education} programs, accessibility and the target population's comfort is far more important than professional ambience. Some of our most attended and successful programs have been located in packing sheds, parking lots beside markets, parks, youth dances, churches, temples, cultural celebrations, block parties, backyards, and the homes of participants. Having a large room with full audio-visual capabilities at a school, hospital or community center can actually decrease attendance. People are more comfortable gathering at the sites they normally frequent. Attending a program at a formal site can be intimidating and uncomfortable. If getting to that site requires transportation, attendance drops even further. Health educators from other community agencies who are invited to participate in our programs feel that using informal sites makes the program less important to the people and they express feeling "out of control" when the usual comforts of electrical outlets, tables, and air conditioning are missing.
While these professionals may feel more comfortable in a formal setting, our target population shows no hesitation in attending programs at less conventional sites. In fact these informal community sites seem to increase the communication between the participants and their level of enjoyment, which means they participate more, stay longer and attend another time.

Feature 7: Choose Appropriate Times We have found that programs for our Spanish speaking mothers are well attended right after the elementary school day starts and again in the afternoon ending as school gets out (see Figure 12). From after school through dinner time, attendance is low. Starting again at 6:30 or 7:00 p.m. brings good attendance when the whole family is involved. Ending by 8:30 p.m. is a must. During the weekend, Saturday late morning and early afternoon is well attended, especially if the whole family is invited. These are times we have found to be effective through experimentation. Other groups will have different preferences. The important thing is to 
find the preferences for the limited English groups in the community. By using times that are appealing to specific groups we increase the number of individuals in attendance who share a language thus increasing their comfort and ability to learn from the program.

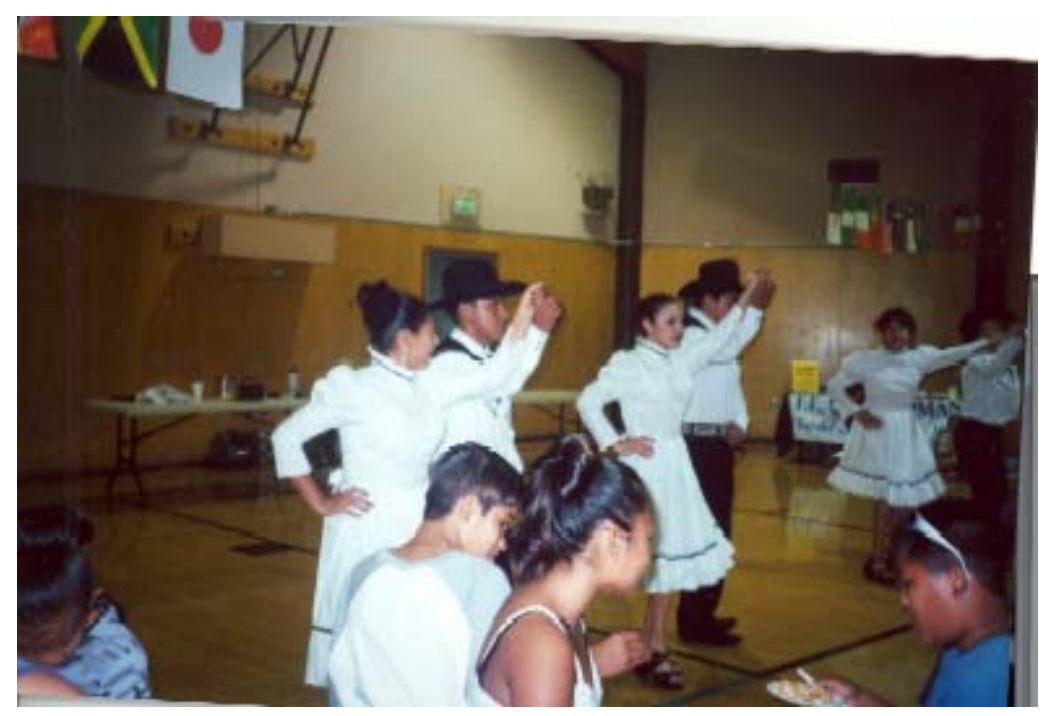

Figure 12

Holding a Health Education Program at a Cultural Event Increases Attendance

\section{Feature 8: Use Small Group Activities}

When the health educator controls all the communication it is difficult to know what prior knowledge the audience has, how much information is being communicated, and what information the audience still needs (see Figure
13). By breaking into groups, individuals can share their information in their primary language and help each other process the information and master the skills. Breaking into groups takes more time than lecturing but it is time well spent.

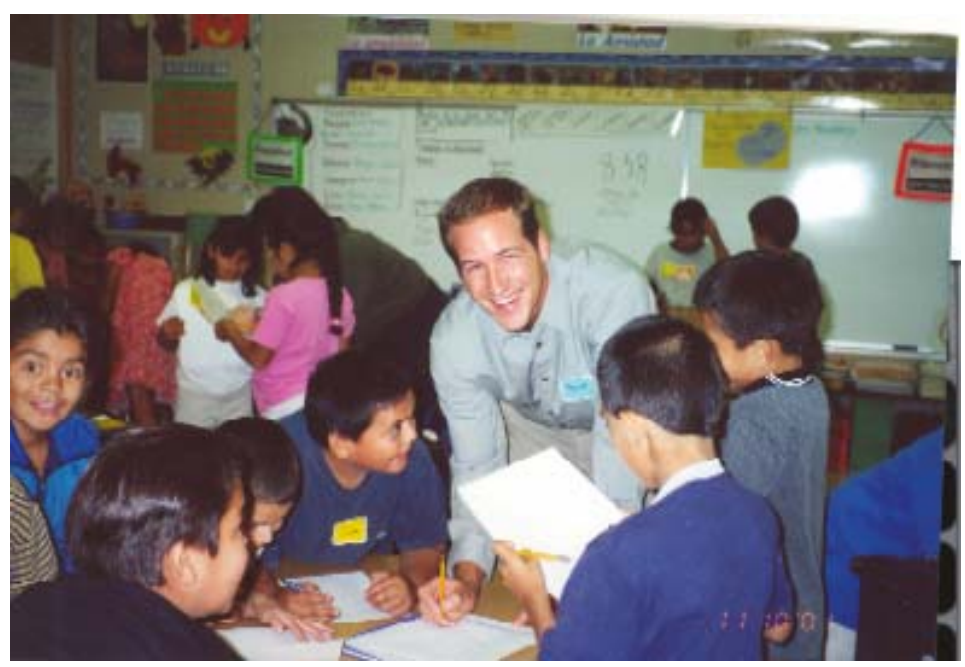

Figure 13

Small Group Work 


\section{Feature 9: Choose an Appropriate}

\section{Length}

An hour and a half seems just about right for any program. If there is a lot of skill building and practice, the program can be increased to two hours. These times are based on the assumption that the program has all of the features described above. If it is a traditional information program then an hour and a half is too long. Our professional peers often say, "If we get the people there, let's really give them a lot because we won't see them again." They then plan three or four hours and sometimes a full day. No one, not even the professionals themselves, can maintain focused attention and interest for that long. Plan a program so enjoyable that the participants wonder where the time went. Then they'll come back.

\section{Not Paper}

Feature 10: Spend Money on Supplies

Health education programs often go overboard on handouts and brochures. A lot of money goes into paper that no one reads and that is often left on the seats or discarded in the trash. The paper that makes it to the car or the house rarely gets read. This is a hard fact for health educators to accept. There is an almost frantic reliance on paper. We have found it more effective to forgo paper completely and focus on getting the message and skills across in the program. The money that would have bought paper products we use to buy food, supplies, visual aids, screening equipment, materials for demonstrations, and children's activities.

\section{Summary}

The ten features described above are guidelines we use in all of our programs for low income, language diverse audiences. They have been identified through five years of trial and error. With these features in place we are enjoying a satisfying rate of participation among members of our community who were thought to be "hard to reach."

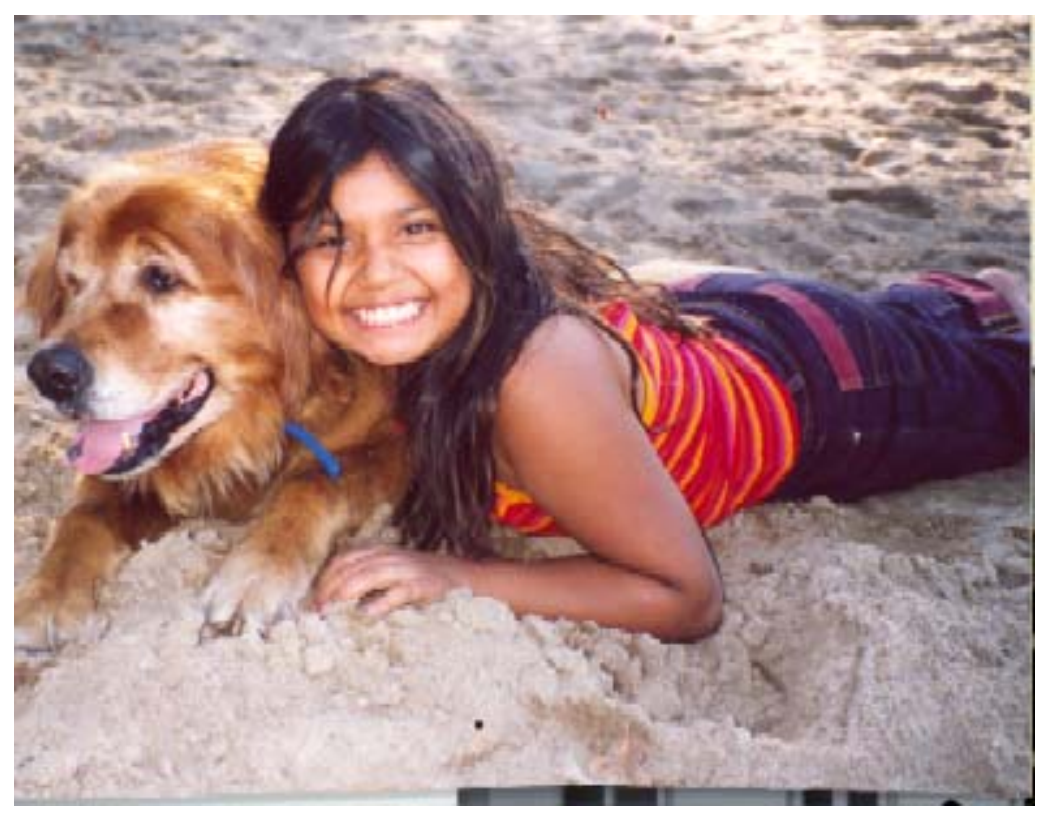

Figure 14

Adios y buena suerte! 


\section{Acknowledgements}

These programs were funded in part by a grant from The California Wellness Foundation, a contract with Butte County Office of Education, and a Strategic Performance Grant from the CSU, Chico College of Behavioral and Social Sciences.

$\underline{\text { Author Information }}$

Mary Portis, DrPH

Department of Health and Community Services

California State University, Chico

E-Mail: mportis@csuchico.edu 